\title{
Elastic modulus of thermally treated fine grained sandstone using non-contact laser extensometer
}

\author{
NN Sirdesai, Bankim Mahanta and TN Singh \\ Indian Institute of Technology Bombay, Mumbai, India \\ nikhil.sirdesai@gmail.com
}

\author{
PG Ranjith \\ Monash University, Clayton, Australia \\ ranjith.pg@monash.edu
}

\begin{abstract}
Processes such as Underground Coal Gasification (UCG), Enhanced Oil Recovery (EOR) and underground disposal of nuclear waste involve the exposure of the surrounding rocks to extreme temperatures. At such high temperatures, the rock suffers substantial structural damage due to the anisotropy in the geotechnical properties of its constituent minerals. Due to variable thermal expansion within minerals, thermal stresses are generated in the rock microstructure which cause change in the fracture pattern. New cracks may develop and pre-existing one may migrate and widen further; thereby reducing the mechanical strength of the rock. In this study, an attempt has been made to study the elastic modulus of thermally treated fine grained sandstone from the Dholpur district of Rajasthan. The elastic modulus was measured by using a MTS LX-Laser Extensometer. The rock specimens were thermally treated at various temperatures for a fixed duration. The change in the rock microstructure was studied viewing the rock specimen under a scanning electron microscope.
\end{abstract}

Keywords_-Young's modulus;sandstone; laser extensometer; strain; thermal treatment

\section{INTRODUCTION}

The study of effect of temperature on rocks is important in various fields of engineering. Success of processes like Underground Coal Gasification (UCG), Enhanced Oil Recovery (EOR), disposal of nuclear waste and deep mining; depend mainly on the stability of the strata. The stability of the strata is compromised when exposed to high temperatures. The geomechanical properties of the rock suffer a substantial damage when exposed to high temperatures [1-5]. Studies conducted on various rock types suggest that the properties are highly susceptible to change in the presence of extreme temperatures. Duration of exposure to high temperatures also accounts for the change in the mechanical properties of the rock [6-11]. Rock, as every other material, expands when subjected to heating. However, the overall expansion is governed by factors that are inherent to a rock specimen. Thermal expansion of the constituent mineral grains and their anisotropies, opening and closure of the pre-existing pores, micro-cracking govern the expansion [12-15]. Expansion in mineral grains occurs along the various crystallographic axes. However, the magnitude and the nature of expansion varies, as seen in the case of calcite and quartz (Table 1). Anisotropy in thermal expansion can also be found at various temperatures within a single mineral grain [14]. Since a rock comprises of many such mineral grains scattered in random orientations, the effect of thermal treatment can lead to the closure or the opening of fissures and pores, thereby affecting the physical, mechanical and transport properties of rock. The magnitude and the duration of heating in the above-mentioned processes varies significantly. Temperatures of over $1200^{\circ} \mathrm{C}$ can be encountered in processes like UCG [11, 16, 17]. Whereas, processes like nuclear waste disposal and geo-thermal energy extraction encounter relatively low temperatures but for a longer period of time. Since the thermal treatment of the strata is diverse, the changes and deformations observed in the strata vary significantly. Therefore, it is imperative to analyze each process thoroughly before designing structures within the strata.

The current study is a part of the ongoing research on the effect of high temperatures on the nearby strata in UCG. The success of a gasification process relies not only in the economic and profitable extraction of the hydrocarbon energy, but also in the safe closure of a gasification 'reactor'. Any UCG process leads to the creation of voids within the strata upon the burning of the underlying coal. Additionally, the geomechanical properties of the surrounding strata are compromised due to the thermal activity. Large, unsupported, thermally compromised cavities created due to the burning of coal, underground, can lead to large scale subsidence and groundwater contamination. A study focused on such changes would help in assessing the environmental effects and the feasibility of the process and thus, prevent substantial economic losses. In this study, specimens of fine grained Indian sandstone of mono-mineralic nature were analyzed to better appreciate the effect of thermal treatment on the geomechanical properties of the rock.

As discussed earlier, thermal anisotropy affects the internal structure of a rock by creating thermal stresses. These thermal stresses later manifest in the form of microcracks which further weaken the strength of the rocks. Additionally at high temperatures, the rock seizes to behave like a brittle material and exhibits plastic-like properties [3]. Therefore, the study of the change in the modulus of elasticity can help in understanding the deformation of the rock. Many techniques have been used to study and observe the elastic modulus. Use of strain gauges, the most common and effective technique, is a direct method of measuring strain present in the rock. However, the technique is time 
taking and uneconomical when the number of samples are high. Indirect techniques of measuring strain, such as the use of laser and video extensometer, Digital Image Co-relation (DIC), provide quick and effective strain measurements and therefore, they are widely used in the fields of mechanical, metallurgical and civil engineering [18-24]. However, the study on the use of laser extensometer in understanding the geomechanical properties of rock is limited. Therefore, in this study, an attempt has been made to evaluate the elastic modulus of thermally treated rocks with the help of a laser extensometer. The study can facilitate in quick and reliable estimation of the elastic modulus of rocks when subjected to high temperatures of thermal treatment. It can also be used in estimating the damage caused by fires to historic buildings.

\section{SAMPLE LOCATION, PREPARATION AND THERMAL TREATMENT}

With the help of a diamond bit core, sandstone blocks from the Dholpur district of Rajasthan, India were cored perpendicular to the bedding plane, in order to recover cylindrical, BX sized rock specimens. The core specimens were air-dried for a period of 5 days to rid them of excess moisture. It was also ensured that the sides of the specimen were flat and parallel to each other. The sandstone belongs to the Upper Bhander group of the Vindhyan super-group as seen in the geological map of the state in figure 1.Dholpur sandstone is characterised by is mono-mineralic and equidimensional nature. The rocks constitutes of more than $95 \%$ quartz and $5 \%$ of matrix.The quartz grains are well sorted, sub-rounded to round in nature and are closely packed rendering the rock relatively compact in nature.

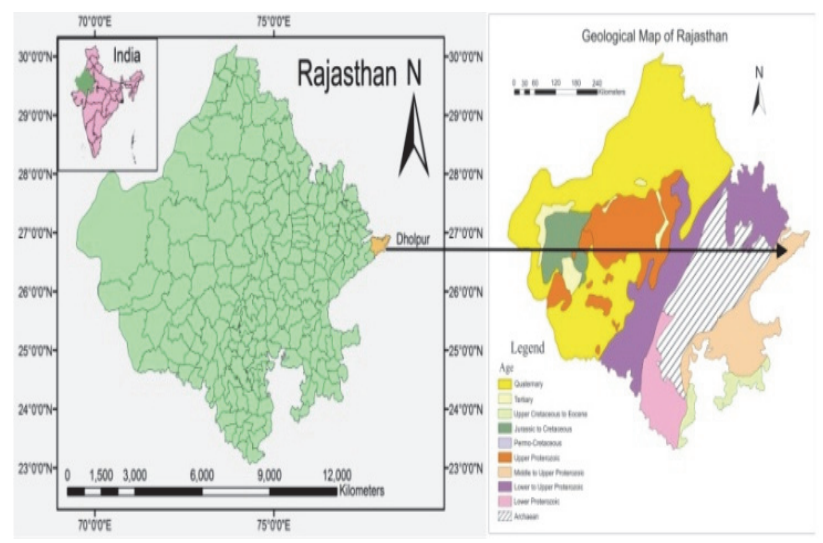

Fig. 1. Geological map of Dholpur district, Rajasthan, India

The rock used in this specimen have trace amounts of iron bearing minerals, therefore rendering the rock light buff in colour. Many major historical monuments in India, including some of the UNESCO World Heritage Sites such as The Red Fort, Stupas of Sarnath and important political structures such as RashtrapatiBhavan and The Parliament have used Dholpur sandstone as building material [25-27]. Therefore, the study on the geo-mechanical behaviour of Dholpur sandstone at elevated temperatures is significant in nature. Consequently, this study can also be used for establishing protocols for the restoration process of fire damaged buildings.
TABLE I. SAMPLE USED IN THIS STUDY

\begin{tabular}{|l|l|}
\hline SAMPLES & $\begin{array}{l}\text { NUMBER OF } \\
\text { SAMPLES TESTED }\end{array}$ \\
\hline Non Treated & 3 \\
\hline T100 & 3 \\
\hline T200 & 3 \\
\hline T300 & 3 \\
\hline T400 & 3 \\
\hline T500 & 3 \\
\hline T600 & 3 \\
\hline T700 & 3 \\
\hline T800 & 3 \\
\hline$T 900$ & 3 \\
\hline$T 1000$ & 3 \\
\hline
\end{tabular}

Before the commencement of the geomechanical testing, the samples were thermally treated in a muffle furnace at temperatures ranging from $100^{\circ} \mathrm{C}$ to $1000^{\circ} \mathrm{C}$ for a period of 5 days. In order to avoid deterioration in the form of thermal shocks, the samples were heated slowly at a constant rate of $5^{\circ} \mathrm{C} / \mathrm{min}[2,15]$. At the end of the heating cycle, the samples were cooled in open air over a duration of 5 days. The total number of samples tested in this study can be seen in table 1 .

\section{Methodology}

The tests were performed at the Rock Science and Rock Engineering (RSRE) Lab, IIT Bombay and the Deep Earth Energy Research (DEER) Lab, Monash University, using a system consisting MTS LX-Extensometer and Instron $100 \mathrm{kN}$ Universal Testing Machine. Figure 2 shows a schematic view of the experimental setup. As seen in the figure, two reflective laser tapes were attached to the sample and a visible beam of laser light from the MTS LX-Extensometer was aimed at the two reflective tapes. The extensometer records the initial difference between the reflective tapes which makes the base for the further strain calculations. As the sample is loaded, the laser marks the movement of the reflective tapes thereby measuring the contraction due to compression. The non-treated and the thermally treated samples were tested in compression to failure at a constant displacement rate of $0.1 \mathrm{~mm} / \mathrm{min}$.

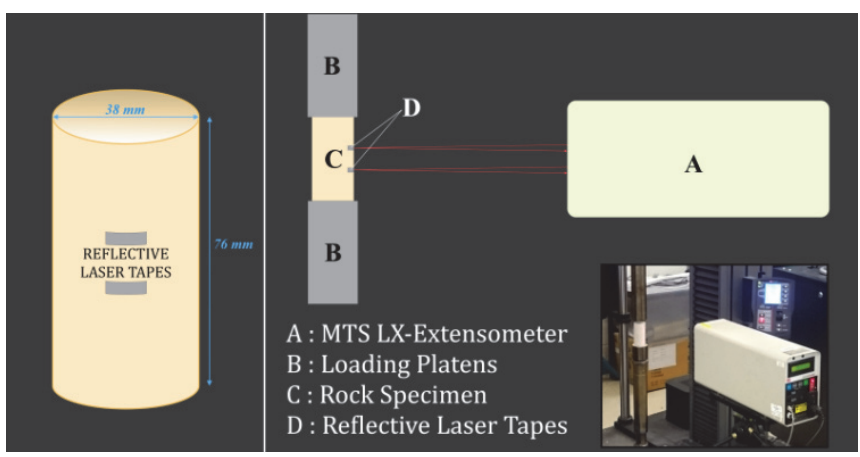

Fig. 2. Schematic diagram of the experimental setup

\section{RESUlTS AND DISCUSSIONS}

The stress-strain behaviour, obtained from the extensometer data for the thermally treated samples, can be 


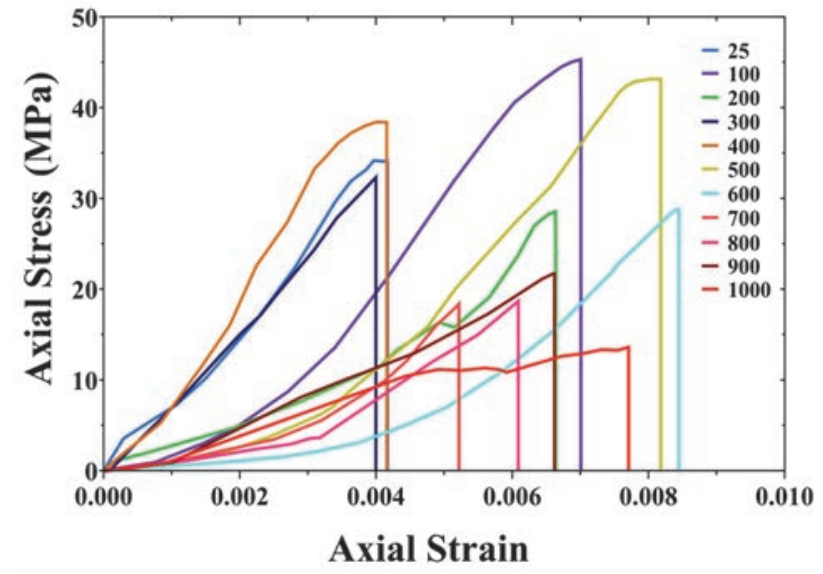

Fig. 3. Stress-Strain behaviour of Dholpur Sandstone as measured from MTS LX-Extensometer

seen in figure 3. As seen in the figure, for temperatures up to $500^{\circ} \mathrm{C}$, the curve obtained for the thermally treated samples $\left(100-400^{\circ} \mathrm{C}\right)$ is similar to the non-treated sample $\left(25^{\circ} \mathrm{C}\right)$. Samples within this temperature zone are highly stiff and therefore, undergo elastic deformation with a brittle to semi-brittle type of failure.

Once heated, the rock along with its constituent minerals, expands. At lower temperatures, the expansion leads to the closure of the pre-existing microcracks and fissures, which renders the rock more compact and stiff in nature. However,

on further heating $\left(>500^{\circ} \mathrm{C}\right)$, the expansion continues which creates new microcracks. The anisotropic thermal behaviourof the mineral grains and $\alpha-\beta$ quartz transition which occurs at $573^{\circ} \mathrm{C}$, lead to anisotropic expansion. Phase change is characterised by a sharp increase in volume. Phase change and the anisotropic expansion exert thermal stress onto the rock fabric which leads to structural damage of the rock [14]. Microcracking under the influence of thermal stresses render the rock less stiff. Also it can be noticed that, at temperatures above $500^{\circ} \mathrm{C}$, the rock behaves like a plastic material undergoing ductile deformations. This is known as transformation plasticity and can be seen in all the rocks studied in the literature $[1,3,6,8,9,11]$.

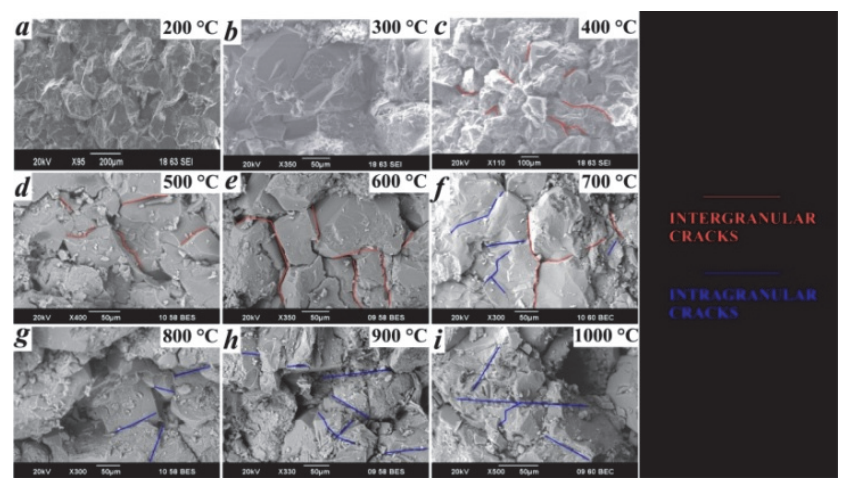

Fig. 4. Microcracks observed through a SEM for thermally treated Dholpur Sandstone

Images obtained from a scanning electron microscope (SEM) were used to observe and better appreciate the effect of thermal treatment. SEM images, seen in figure 4, suggests that the rock fabric sustains considerable damage at high temperatures. However, at low temperatures, thermal expansion leads to expansion of the mineral grains which result in formation of cracks around the grain boundaries. These are the intergranular cracks. As the temperature rises, further expansion and dilation leads to formation of cracks within the mineral grain, known as intragranular cracks. Combination of intergranular and intragranular cracks leads to deterioration of the mineral assemblage, which causes weakening of the material and reduction in cohesion. The magnitude of damage at $1000^{\circ} \mathrm{C}$ is maximum as seen in figure 4, with the grains dislodged from the fabric.

The thermal treatment also affects the compressive strength of the rock, as seen in figure 5. At lower temperatures, as the mineral grains expand, the pre-existent microcracks fill up, rendering the rock compact. A decrease in the density of microcracks and the shrinkage of the initial pores leads to an increase in the load bearing capacity of the rock. This can be observed at temperatures between 200$400^{\circ} \mathrm{C}$. The initial dip in the compressive strength can be attributed to the redistribution of stresses due to the filling of cracks and crevices within the rock fabric. Similar kind of behaviour has been observed for various sandstones studied in the literature $[7,11,14]$. However, the studies carried out on sedimentary rocks affirm with the decrease of the mechanical properties after a certain temperature limit. This limit, also known as the critical temperature zone (CTZ), indicate the deterioration of internal structure of rock due to extensive expansion and creation of inter and intragranularmicrocracks $[8,10]$. The CTZ for Dholpur sandstone can therefore be confirmed at temperatures between $300-500^{\circ} \mathrm{C}$. At temperatures beyond $\mathrm{CTZ}$, due to rapid formation of microcracks, the grains give way to microcracks and the rock loses its ability to bear load, as seen in figure 4 . The compressive strength of Dholpur sandstone at $1000^{\circ} \mathrm{C}$ drops to more than half of that at normal atmospheric conditions.

The effect of thermal treatment on the normalised elastic modulus was plotted and can be seen in figure 6. Processes like closing, formation and extension of microcracks affect the elastic modulus of any rock [6,11]. Extension and formation lead to creation of crevices which thereby affected

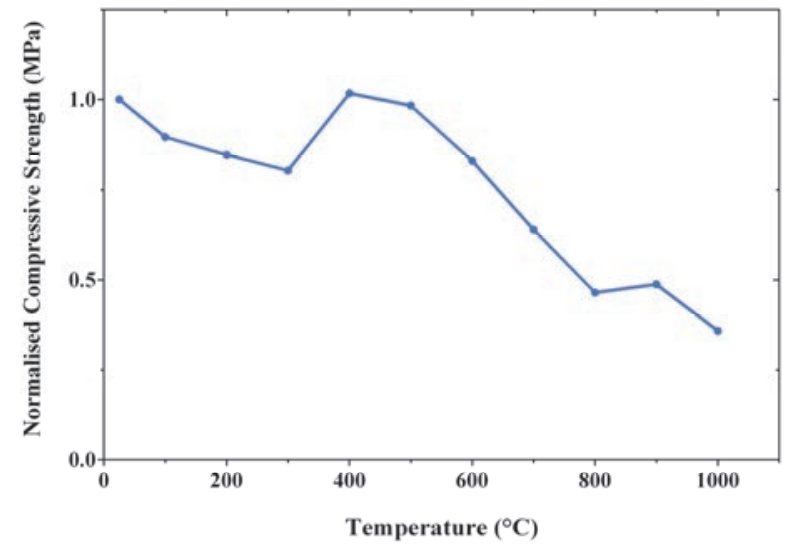

Fig.5. Normalized compressive strength of thermally treated Dholpur Sandstone 


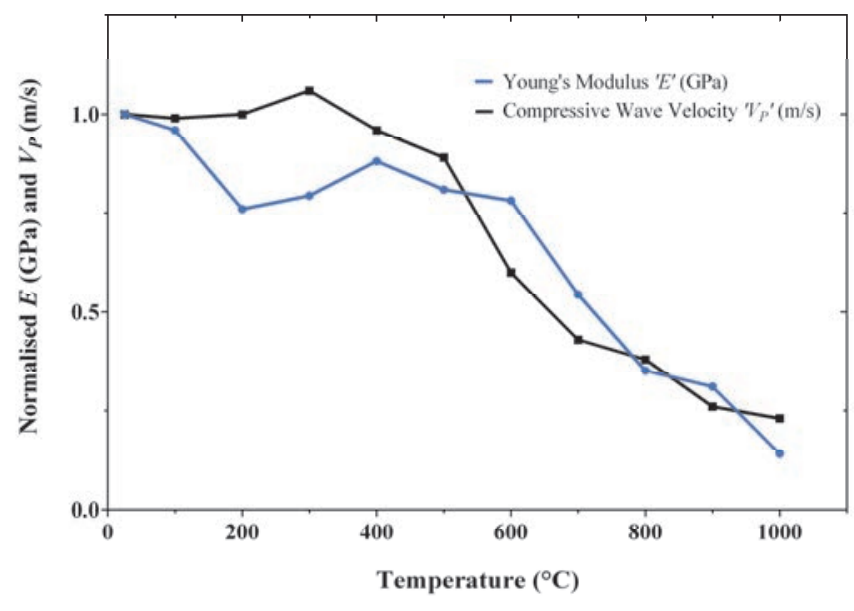

Fig.6. Normalised Young's modulus (E) and compressive wave velocity (VP) of thermally treated Dholpur Sandstone

the structural integrity of the rock. The rocks analysed in these studies show a similar trend when exposed to high temperatures. It can also be seen that, the duration and the nature of the thermal treatment provided to a certain rock type can widely affect the mechanical properties. Long and constant exposure lead to deeper and profound extension of the cracks [10]. In this study, since the rock was heated for a period of 5 days, the thermal treatment brought about a definite change to the microstructure as seen in figure 4 . In order to conceptualize the damage to the rock microstructure, it is vital to study the change in the ultrasonic wave velocities $[14,28]$. The elastic modulus ' $E$ ', for Dholpur sandstone, decreases with the increase in temperature. However, at temperatures between $200-400^{\circ} \mathrm{C}$, due to the closing of the microcracks and increase in relative stiffness, there is a noticeable increase in the elasticity of the rock, which can also be seen in figure 5 , as the increase in the compressive strength.The closing of the pores and microcracks, which are the basically the voids present in the rock, the compressive wave velocity (VP) increases. However, as the temperatures increase beyond the CTZ, the microstructure starts crumbling which leads to a decrease in the wave velocity.At these temperatures due to the effect of thermal softening, the cohesion between the mineral grains decreases and the rocks start exhibiting plastic and ductile behaviour thereby leading to a decrease in the elastic modulus of the rock $[3,6,11]$.

\section{CONCLUSIONS}

The change in geomechanical properties such as compressive strength, stress-strain behavior, elastic modulus and compressional wave velocities (VP) due to thermal treatment were studied for Dholpur sandstone using a MTS LX Laser Extensometer. The rock was selected for its mono-mineralic characteristic to better appreciate the magnitude of the thermal damage. The rock was chosen for its geographical significance as it has been used as a major building material in various vital political and cultural monuments. This study can be used in processes like Underground Coal Gasification (UCG), mine fires and resurrection and renovation of fire damaged buildings.
By performing this study, it was concluded that exposure to high temperatures has a profound effect on strength and the deformation of Dholpur sandstone. The nature of the deformation changes at temperatures above $500^{\circ} \mathrm{C}$ as the rock starts exhibiting plasticity beyond the elastic stage. While brittle failure was observed will $600^{\circ} \mathrm{C}$, the rocks failed in ductile mode above $800^{\circ} \mathrm{C}$. The change in the properties is largely governed by microcracks. Closure of the microcracks around the grains lead to an increase in the stiffness which thereby increased the load bearing capacity of the rock. However, beyond $400-500^{\circ} \mathrm{C}$, due to anisotropic expansion of the grains along various crystallographic axes, formation and extension of new microcracks was observed and was thereby analyzed by performing SEM studies. This transition point or zone, termed as the Critical Temperature Zone (CTZ), is the temperature window beyond which the formation of new microcracks leads to the decrease in intergrain cohesion thereby causing the rock to exhibit plastic behavior. SEM studies revealed the formation of intergranular cracks at lower temperature. However at high temperatures, due to further expansion of the grains, cracks start emerging within the grain body. The formation of intragranular cracks lead to complete deterioration of the mineral assemblage. The rock microstructure suffers profound damage causing a sharp decrease in the elastic modulus and the load bearing capacity of the rock.

The study, however, conceptualizes the effect of thermal treatment on one particular rock type and therefore, for processes like UCG and mine fires due to vast variety of rocks present in the strata, it is imperative to study the effect of exposure to high temperatures on individual rock types before the commencement of the process. This will help in minimizing the damage to the strata and help in averting disasters such as subsidence and groundwater contamination. Thorough understanding of the range of effects of thermal treatment between different reservoir rocks will help in increasing the efficiency and the reliability on these processes.

\section{REFERENCES}

[1] V. Brotóns, R. Tomás, S. Ivorra, and J. C. Alarcón, "Temperature influence on the physical and mechanical properties of a porous rock: San Julian's calcarenite," Engineering Geology, vol. 167, pp. 117-127, 2013.

[2] M. Hajpál and Á. Török, "Mineralogical and colour changes of quartz sandstones by heat," Environmental Geology, vol. 46, 2004.

[3] P. G. Ranjith, D. R. Viete, B. J. Chen, and M. S. A. Perera, "Transformation plasticity and the effect of temperature on the mechanical behaviour of Hawkesbury sandstone at atmospheric pressure," Engineering Geology, vol. 151, pp. 120-127, 2012.

[4] H. Tian, T. Kempka, N.-X. Xu, and M. Ziegler, "Physical Properties of Sandstones After High Temperature Treatment," Rock Mechanics and Rock Engineering, vol. 45, pp. 1113-1117, 2012.

[5] V. Vishal, S. Pradhan, and T. Singh, "Tensile strength of rock under elevated temperatures," Geotechnical and Geological Engineering, vol. 29, pp. 1127-1133, 2011.

[6] P. K. Gautam, A. K. Verma, S. Maheshwar, and T. N. Singh, "Thermomechanical Analysis of Different Types of Sandstone at Elevated Temperature," Rock Mechanics and Rock Engineering, vol. 49, pp. 1985-1993, 2015. 
[7] M. Hajpál, "Changes in sandstones of historical monuments exposed to fire or high temperature," Fire Technology, vol. 38, pp. 373-382, 2002.

[8] B. Mahanta, T. N. Singh, and P. G. Ranjith, "Influence of thermal treatment on mode I fracture toughness of certain Indian rocks," Engineering Geology, vol. 210, pp. 103-114, 8/5/ 2016

[9] X. Mao, L. Zhang, R. Liu, and D. Ma, "Mechanical and Thermal Damage Properties of Sandstone at High Temperatures," Electronic Journal of Geotechnical Engineering, vol. 19, pp. 3137-3150, 2014.

[10] N. N. Sirdesai, T. N. Singh, P. G. Ranjith, and R. Singh, "Effect of Varied Durations of Thermal Treatment on the Tensile Strength of Red Sandstone," Rock Mechanics and Rock Engineering, pp. 1-9, 2016.

[11] H. Tian, T. Kempka, S. Yu, and M. Ziegler, "Mechanical Properties of Sandstones Exposed to High Temperature," Rock Mechanics and Rock Engineering, vol. 49, pp. 321-327, 2015.

[12] S. P. Clark, Handbook of physical constants vol. 97: Geological Society of America, 1966.

[13] J. T. Fredrich and T.-f. Wong, "Micromechanics of thermally induced cracking in three crustal rocks," Journal of Geophysical Research: Solid Earth, vol. 91, pp. 12743-12764, 1986.

[14] W. H. Somerton, Thermal properties and temperature-related behavior of rock/fluid systems vol. 37: Elsevier, 1992.

[15] H. Yavuz, S. Demirdag, and S. Caran, "Thermal effect on the physical properties of carbonate rocks," International Journal of Rock Mechanics and Mining Sciences, vol. 47, pp. 94-103, 2010.

[16] E. Burton, J. Friedmann, and R. Upadhye, "Best Practices in Underground Coal Gasification," Lawrence Livermore National Laboratory2007.

[17] N. N. Sirdesai, R. Singh, T. N. Singh, and P. G. Ranjith, "Numerical and experimental study of strata behavior and land subsidence in an underground coal gasification project," Proceedings of the International Association of Hydrological Sciences, vol. 372, pp. 455$-462,2015$.

[18] M. L. Bartlett and A. Saxena, "The use of laser extensometer to study the behavior of short fatigue cracks," Engineering Fracture Mechanics, vol. 30, pp. 655-665, 1988/01/01 1988.

[19] D. F. Carroll, S. M. Wiederhorn, and D. E. Roberts, "Technique for Tensile Creep Testing of Ceramics," Journal of the American Ceramic Society, vol. 72, pp. 1610-1614, 1989.

[20] M. Di Prima, M. Lesniewski, K. Gall, D. McDowell, T. Sanderson, and D. Campbell, "Thermo-mechanical behavior of epoxy shape memory polymer foams," Smart Materials and Structures, vol. 16, p. 2330, 2007.

[21] A. J. Karnie and E. E. Day, "A laser extensometer for measuring strain at incandescent temperatures," Experimental Mechanics, vol. 7, pp. 485-489, 1967.

[22] I. Koh, A. López, B. Helgason, and S. J. Ferguson, "The compressive modulus and strength of saturated calcium sulphate dihydrate cements: Implications for testing standards," Journal of the Mechanical Behavior of Biomedical Materials, vol. 34, pp. 187-198, $6 / / 2014$.

[23] H. Liu, X. Zhao, Y. Bai, R. Singh, S. Rizkalla, and S. Bandyopadhyay, "The effect of elevated temperature on the bond between high modulus carbon fibre-reinforced polymer sheet and steel," Australian Journal of Structural Engineering, vol. 15, pp. 355366, 2014.

[24] M. Yonekawa, T. Ishii, M. Ohmi, F. Takada, T. Hoshiya, M. Niimi, et al., "Development of a remote-controlled fatigue test machine using a laser extensometer for investigation of irradiation effect on fatigue properties," Journal of Nuclear Materials, vol. 307-311, Part 2, pp. 1613-1618, 12// 2002.

[25] CGWB, "Groundwater Scenario, Dholpur District - Western Region of Jaipur," ed. Jaipur: Ministry of Water Resources, Government of India., 2010.

[26] DMG-Rajasthan. (2006, August 15). Sandstone - Rajasthan. Available: www.dmg-raj.org/sandstone.html
[27] UNESCO. (2015, 1 May). India - UNESCO World Heritage Centre. Available: http://whc.unesco.org/en/statesparties/in

[28] J. C. Jaeger, N. G. W. Cook, and R. Zimmerman, Fundamentals of Rock Mechanics: Wiley, 2009. 